\title{
Data comparison between pharmacological induction of labour and spontaneous delivery. A single centre experience
}

\author{
Roberta Granese ${ }^{1 *}$, Gloria Calagna2 ${ }^{2}$ Alessandro Sollano ${ }^{3}$, Stefania Mondello ${ }^{4}$, Angela Sicilia ${ }^{5}$, \\ Roberta Grasso ${ }^{6}$, Gaspare Cucinella ${ }^{7}$, Onofrio Triolo ${ }^{8}$ \\ ${ }^{1}$ Department of Obstetrics and Gynecology, University Hospital "G. Martino", via Consolare Valeria, Gazzi, Messina, Italy \\ ${ }^{2}$ Obstetrics and Gynecology, University of Palermo, via A. Giordano 3, 90100 Palermo, Italy \\ ${ }^{3}$ Department of Obstetrics and Gynecology, University Hospital "G. Martino", via Consolare Valeria, Gazzi, Messina, Italy \\ ${ }^{4}$ Department of Biomedical, Odontoiatric and Morphological and Functional Imaging Sciences, University Hospital "G. Martino", \\ via Consolare Valeria, Gazzi, Messina, Italy \\ ${ }^{5}$ Department of Obstetrics and Gynecology, University Hospital "G. Martino", via Consolare Valeria, Gazzi, Messina, Italy \\ ${ }^{6}$ Department of Obstetrics and Gynecology, University Hospital "G. Martino", via Consolare Valeria, Gazzi, Messina, Italy \\ 7Department of Obstetrics and Gynecology, "Villa Sofia-Cervello" Hospital, University of Palermo via Trabucco 180, \\ 90100 Palermo, Italy \\ ${ }^{8}$ Department of Obstetrics and Gynecology, University Hospital "G. Martino", via Consolare Valeria, Gazzi, Messina, Italy
}

\begin{abstract}
Objectives: To assess the differences in the maternal and fetal outcomes between pharmacological induced and spontaneous labour in nulliparous women.

Material and methods: Observational cohort study carried out over a period of 2 years. Inclusion criteria: nulliparous singleton pregnancies, with cephalic fetal presentation, elective labour induction with intra-vaginal prostaglandin E2 (PGE2) gel (Prepidil ${ }^{\otimes} 2 \mathrm{mg}$ ) at a gestational age of 41 weeks. Control group: patients who entered labour spontaneously at a gestational age of $\geq 40$ weeks. The main demographic maternal characteristics and intra- and postpartum data were extracted from computer records and obstetrics diaries and were used for the analysis.

Results: One hundred and three patients with induction of labour and 97 with spontaneous labour were enrolled. Cesarean delivery was performed in 18 cases (17.5\%), all in the induction group. There were no differences in newborn weights between the 2 groups while both the 1-minute and 5-minute Apgar scores were significantly higher in the spontaneous group ( $p=0.014$ and $p=0.0003$, respectively). Women in the induction group had a significantly longer duration of I stage labour in comparison with spontaneous group $(\mathrm{p}<0.0001)$.

Conclusions: Primiparous women whose labour was induced spent a longer time in labour than women who presented in spontaneous labour. Clinicians should keep in mind that a slow rate of dilation in a woman being induced may be normal. For this reason, an arrest diagnosis needs to be carefully considered.
\end{abstract}

Key words: induction of labour, spontaneous labour, neonatal outcome, prostaglandin E2

Ginekologia Polska 2016; 87, 10: 697-700

\section{INTRODUCTION}

Induction of labour involves the artificial stimulation of uterine contractions with the aim of achieving vaginal delivery, and is performed in approximately $15 \%$ of all pregnancies [1].
The clinical requirement for induction of labour arises from circumstances in which it is believed that the outcome of the pregnancy will be better if it is artificially interrupted rather than being left to follow its natural course [2]. Most 
methods of induction try to achieve activation of cervical and uterine changes and have been widely studied in the last few years. Data on the efficacy of current methods report two main types of techniques: pharmacological and non-pharmacological methods [3]. The most commonly used pharmacological method of induction of labour is by prostaglandins, mainly by vaginal administration [3].

Previous studies have compared spontaneous and induced labour in nulliparous women, with no unanimous results [4-8]. Some authors showed an increased rate of caesarean delivery, uterine hyper-stimulation and newborns with low Apgar scores, in the induced labour group [4, 7-13]; on the contrary, other studies have shown a similar or lower rate of these outcomes between induced and spontaneous deliveries [5, 14-16].

However, many authors did not examine homogeneous groups of women, adding a relevant study bias that could be the cause of the different achieved results on the topic $[12,17,18]$

With regard to arrest disorders, it was also reported that the course of labour in women undergoing induction proceeded slower than in spontaneous labour, above all before $6 \mathrm{~cm}$ of dilatation and, for this reason, these women could be diagnosed with arrest of dilation, prematurely $[19,20]$.

The aim of this study is to assess the differences in maternal and fetal outcomes between medically induced delivery, using prostaglandin E2 (PGE2), in nulliparous women at or above 41 weeks' gestation and spontaneous labour in nulliparous women at $\geq 40$ weeks of gestation.

\section{MATERIAL AND METHODS}

This is an observational cohort study carried out on women who delivered at the Department of Gynecology and Obstetrics of the University Hospital of Messina, from January 2013 to June 2015. Ethical consent for the study to be carried out was given by the Local Ethics Committee.

Inclusion criteria were: nulliparous singleton pregnancies, with cephalic fetal presentation, who had elective induction of labour with the use of intra-vaginal PGE2 gel (Prepidil $^{\circledR} 2 \mathrm{mg}$ ) at a gestational age of 41 weeks and 3 days.

We considered exclusion criteria as: multiple pregnancies, non-vertex presentation, high risk pregnancy for gestational or pre-existing maternal diseases, fetal anomalies, intra-uterine fetal growth restriction, intrauterine death, oligohydramnios, premature rupture of membranes, previous uterine surgery (including caesarean section), partoanalgesia, induction of labour with the use of other pharmacological methods or absence of informed consent.

Using the same criteria, a control group was selected from patients who entered labour spontaneously at $\geq 40+0$ weeks of gestation age, during the study period.
Data were extracted from computer records and obstetrics diaries. The main demographic maternal characteristics were recorded including maternal age, body mass index (BMI), smoker/non-smoker, and gestational age at delivery. Intra- and postpartum data collected included: Bishop's Score, length of I and II labour stages (expressed in minutes), delivery method (vaginal or caesarean), possible obstetric vagino-perineal injuries (for vaginal delivery), complications (such as need for blood transfusion or fever during labour), hospital stay after delivery (days); moreover, we considered neonatal outcome variables such as Apgar score (at 1 and 5 minutes), birth weight and possible neonatal complications (such as neonatal sepsis, birth asphyxia, neonatal trauma or neonatal recovery in intensive care unit).

To calculate the I stage of labour, we considered all the time elapsed from the onset of labor up to the reaching of complete dilation, the active phase of labour was defined as the increased rate of cervical dilation; the II stage of labour was calculated considering the time from the complete cervix dilatation to the complete expulsion of the fetus [21]. To avoid misclassification, women who underwent partoanalgesia and those who received oxytocin during labour were excluded.

Labour induction was offered to all the pregnant women in absence of uterine contractions until $41+3$ weeks. At the day of the procedure, women undergoing induction of labour were admitted to our Unit in the morning and received intra-vaginal PGE2 gel (Prepidil' 2 mg) according to the National Institute for Health and Clinical Excellence's (NICE) guidance [21]. These guidelines recommend induction of labour between $41+0$ and $42+0$ weeks. The protocol consists of one dose, followed by a second dose after 6 hours if labour is not established (up to a maximum of 2 doses).

Although the definitions of failed induction can vary, in our Unit, when induction fails after $\mathbf{2}$ doses of PGE2 (Prepidil $2 \mathbf{~ m g}$ ), the woman is counseled and given a maximum of two further doses after a rest of 24 hours. If, finally, there is no cervical response, the woman is delivered by caesarean section, in accordance with NICE recommendations [21].

\section{Statistical analysis}

Continuous variables were summarized as mean \pm standard deviation (SD) for normally distributed data or median and interquartile range (IQR) for normally distributed data. Categorical variables were summarized as number (percentage). Differences between 2 groups were assessed using unpaired Student's t-test or Mann-Whitney U test, as appropriate. Pearson Chi-square or Fisher's exact test was used to compare frequencies. Relationships between continuous variables were assessed by bivariate correlations (Spearman's r). 
All hypothesis tests conducted were 2-tailed and a $\mathrm{p}$ value $<0.05$ was considered significant. All statistical analyses were conducted using SAS (SAS version [9.2] of the SAS System. Copyright $\odot$ 2002-2008 by SAS Institute Inc., Cary, NC, USA).

\section{RESULTS}

A total of 200 nulliparous women were enrolled in the study. One hundred and three patients had induction of labour and 97 delivered following spontaneous labour. The study groups were well matched with regard to demographic characteristics, which are reported in Table 1.

Mean gestational age was 41.3 and 40.3 weeks, respectively, in the induction labour group and in the spontaneous labour group $(p=0.05)$. Caesarean delivery was performed in 18 cases (17.5\%), all in the induction group. Indications for caesarean section were failure of dilatation in $78 \%$ of cases and fetal distress in the remaining cases (22\%). No maternal blood transfusion was required; no cases of fever, postpartum hemorrhage or other complications occurred.

Both the 1-minute and the 5-minute Apgar scores were significantly higher in the spontaneous group $(p=0.014$ and $p=0.0003$, respectively) (Tab. 2). There were no differences in newborn weights between the 2 groups $(p>0.05)$ and no neonatal complication occurred in either groups. Intra- and post-partum data for both study groups are shown in Table 2.

Compared to the spontaneous group, women in the induction group had a significantly longer duration of I stage labour ( $p<0.0001)$, while the duration of II stage was similar in the 2 study groups $(p=0.85)$.

Among women who had induction of labour, duration of I stage labour was not associated with maternal age, BMI, or newborn weight ( $p>0.05$ ), but was positively correlated with gestational age $(R=0.26, P=0.019)$. No correlations were found among women in spontaneous labour.

Episiotomy and perineal laceration rates were similar between the 2 groups (Tab. 2). Finally, the time of hospitalization after delivery was similar in both group ( $p>0.05)$.

Table 1. Characteristics of recruited subjects

\begin{tabular}{|l|c|c|c|}
\hline & $\begin{array}{c}\text { Induced } \\
(\mathbf{n = 1 0 3 )}\end{array}$ & $\begin{array}{c}\text { Spontaneous } \\
(\mathbf{n = 9 7})\end{array}$ & $\mathbf{P}$ \\
\hline Age (years) & $30.02 \pm 5.84$ & $29.05 \pm 5.61$ & 0.23 \\
\hline BMI $\left[\mathrm{kg} / \mathrm{m}^{2}\right]$ & $27.24 \pm 3.84$ & $26.54 \pm 5.53$ & 0.31 \\
\hline Gestational age (week) & 41.3 & 40.3 & 0.05 \\
\hline Smokers, $\mathbf{n}(\%)$ & $8(7.8 \%)$ & $7(7.2 \%)$ & 0.55 \\
\hline Bishop score* & $6(6-7)$ & $6(6-7)$ & 0.21 \\
\hline
\end{tabular}

*Data expressed as median and interquartile range Data expressed in mean \pm SD

\begin{tabular}{|c|c|c|c|}
\hline & $\begin{array}{l}\text { Induced } \\
(n=103)\end{array}$ & $\begin{array}{l}\text { Spontaneous } \\
\quad(n=97)\end{array}$ & $\mathbf{P}$ \\
\hline \multicolumn{4}{|l|}{ Duration of labour (min)* } \\
\hline IStage & $\begin{array}{c}430(267.5- \\
712.5)\end{array}$ & $270(180-428)$ & $<0.0001$ \\
\hline II Stage & $30(22-36.5)$ & $29(20-37)$ & 0.85 \\
\hline Delivery method, n (\%) & & & $<0.0001$ \\
\hline Vaginal & $85(82.5)$ & $97(100)$ & \\
\hline Caesarean & $18(17.5)$ & 0 & \\
\hline \multicolumn{4}{|l|}{ Newborn Apgar Score } \\
\hline 1 minute & $9.05 \pm 1.004$ & $9.35 \pm 0.66$ & 0.014 \\
\hline 5 minute & $9.74 \pm 0.5$ & $9.95 \pm 0.22$ & 0.0003 \\
\hline Newborn weight [gr] & $3343 \pm 525.6$ & $3303 \pm 405$ & 0.55 \\
\hline Episiotomy, n (\%) & & & 0.83 \\
\hline No & $38(44.71)$ & $42(43.3)$ & \\
\hline Yes & 47 (55.29) & $55(56.7)$ & \\
\hline Perineal laceration, n (\%) & & & 0.07 \\
\hline No & $66(64.1)$ & $51(52.6)$ & \\
\hline Yes & $37(35.09)$ & $46(47.4)$ & \\
\hline $\begin{array}{l}\text { Perineal laceration grade, } \\
\text { n (\%) }\end{array}$ & & & 0.15 \\
\hline 1 & $29(78.38)$ & $40(87)$ & \\
\hline ॥ & $8(21.62)$ & $6(13)$ & \\
\hline
\end{tabular}

*Data expressed as median and interquartile range Data expressed in mean \pm SD

\section{DISCUSSION}

Our study confirmed literature data reporting a significantly higher rate of caesarean section in women whose labour was induced (in our series, $17.5 \%$ of cases which occurred only in the induction group). This finding could be related to the longer duration of I stage of labour [5-12, $22,23]$.

Harper et al. reported that the progression of labour in nulliparous women who undergo induction was significantly slower than in spontaneous labour and also compared to the current accepted definitions of arrest disorders (i.e.: no cervical dilation for 2 hours) [19, 24]. Moreover, according to this study, the active phase of labour in these women begins after $6 \mathrm{~cm}$, much later than current definitions of $3-4 \mathrm{~cm}[24,25]$. For this reason, a significant number of caesarean deliveries for arrest disorders could be performed prematurely in women where labour is induced.

We found that cervical dystocia, as failure in dilatation (78\% of cases) was the main indication for a caesarean section in nulliparous women with induction of labour. But the need for induction of labour in pregnant women probably 
indicates an intrinsic predisposition to poor uterine action [13], and it is possible that it could not be corrected readily by medical stimulation.

Another emergent finding was the positive correlation between increase of I stage duration and gestational age of the pregnant woman.

Episiotomy and lacerations were similarly represented in both groups, but, conversely, in spontaneous labour, women who experienced perineal lacerations had a significantly greater BMI than those who did not have this complication (mean $28.43 \pm 5.4$ vs. $24.85 \pm 5.14 \mathrm{~kg} / \mathrm{m}^{2}, \mathrm{p}=0.0031$ ).

Neonatal outcome was similar in both groups of women except for 1-minute and 5-minute Apgar scores, which were significantly higher in the spontaneous group, in contract with the report by Selo Ojemart et al., which found a higher rate of adverse neonatal outcomes in the induction group [13].

Analyzing international literature on the topic, many confounding variables are generally identified in this kind of study, above all, the heterogeneity of the characteristics of enrolled patients $[1,6,7,12,14,26]$. For this study, we chose very strict selection criteria to reduce variability and it could be a point of strength of our analysis.

However, even this study has some limitations. First of all, the relatively small size of the cohort of the included patients. Then, a bias of our study could be that I stage of labour was analyzed from $3 \mathrm{~cm}$ of dilatation as women admitted in our Hospital in spontaneous labour, generally, have a cervical dilatation equal to or greater than $3 \mathrm{~cm}$. Therefore, we were unable to compare or comment on the cervical ripening phase of labour or on the length of labour before $3 \mathrm{~cm}$, in the two study groups.

In conclusion, in our series, nulliparous women whose labor was induced spent a longer time in I stage of labor than women who presented in spontaneous labor. As a slow rate of dilation in a woman being induced may be normal, an arrest diagnosis needs to be carefully considered and might not indicate an immediately need for caesarean delivery.

Prospective trials on labour management in a larger sample of women could be useful to better understand if greater tolerance and waiting in women with induced labour could change caesarean delivery rates in this category of women.

\section{Conflict of interest}

Authors don't have any sources of financial support to disclosure.

\section{REFERENCES}

1. Thorsell $\mathrm{M}$, Lyrenäs $\mathrm{S}$, Andolf $\mathrm{E}$, [et al.]. Induction of labor and the risk for emergency cesarean section in nulliparous and multiparous women. Acta Obstet Gynecol Scand. 2011, 90, 1094-1099.

2. Ciancimino L, Laganà AS, Chiofalo $B$, [et al.]. Would it be too late? A retrospective case-control analysis to evaluate maternal-fetal outcomes in advanced maternal age. Arch Gynecol Obstet. 2014, 29, 1109-1114.

3. National Collaborating Centre for Women's and Children's Health (UK). Induction of Labour. London: RCOG Press. 2008.

4. Cammu H, Martens G, Ruyssinck G, [et al.]. Outcome after elective labor induction in nulliparous women: a matched cohort study. Am J Obstet Gynecol. 2002, 186, 240-244.

5. Hannah ME, Hannah WJ, Hellmann J, [et al.]. Induction of labor as compared with serial antenatal monitoring in post-term pregnancy. A randomized controlled trial. The Canadian Multicenter Post-term Pregnancy Trial Group. N Engl J Med. 1992, 326, 1587-1592 (Erratum in: NEngl J Med. 1992, 327, 368).

6. Prysak M, Castronova FC. Elective induction versus spontaneous labour: a case control analysis of safety and efficacy. Obstet Gynecol. 1998, 92, 47-52.

7. Seyb ST, Berka RJ, Socol ML, [et al.]. Risk of caesarean delivery with elective induction of labour at term in nulliparous women. Obstet Gynecol. 1999, 94, 600-607.

8. Yeast JD, Jones A, Poskin M. Induction of labour and the relationship to caesarean delivery: a review of 7001 consecutive inductions. Am J Obstet Gynecol. 1999, 180 (3 Pt 1), 628-633.

9. Dublin S, Lydon-Rochelle M, Kaplan RC, [et al.]. Maternal and neonatal outcomes after induction of labor without an identified indication. $\mathrm{Am}$ J Obstet Gynecol. 2000, 183, 986-994.

10. Luthy DA, Malmgren JA, Zingheim RW. Caesarean delivery after elective induction in nulliparous women: the physician effect. Am J Obstet Gynecol. 2004, 191, 1511-1515.

11. Macer JA, Macer CL, Chan LS. Elective induction versus spontaneous labor: a retrospective study of complications and outcome. Am J Obstet Gynecol. 1992, 166, 1690-1696.

12. Maslow AS, Sweeny AL. Elective induction of labor as a risk factor for cesarean delivery among low-risk women at term. Obstet Gynecol. 2000, 95, 917-922.

13. Selo-Ojeme D, Rogers $C$, Mohanty A, [et al.]. Is induced labour in the nullipara associated with more maternal and perinatal morbidity? Arch Gynecol Obstet. 2011, 284, 337-341.

14. Caughey AB, Sundaram V, Kaimal AJ, [et al.]. Systematic review: elective induction of labor versus expectant management of pregnancy. Ann Intern Med. 2009, 151, 252-263.

15. Gulmezoglu AM, Crowther CA, Middleton P. Induction of labour for improving birth outcomes for women at or beyond term. Cochrane Database Syst Rev. 2006, 18, CD004945.

16. Sanchez-Ramos L, Olivier F, Delke I, [et al.]. Labor induction versus expectant management for post-term pregnancies: a systematic review with meta-analysis. Obstet Gynecol. 2003, 101, 1312-1318.

17. Beebe L, Beaty C, Rayburn W. Immediate neonatal outcomes after elective induction of labor. J Reprod Med. 2003, 52, 173-175.

18. Glantz JC. Elective induction vs. spontaneous labor associations and outcomes. J Reprod Med. 2005, 50, 235-240.

19. Harper LM, Caughey AB, Odibo AO, [et al.]. Normal progress of induced labor. Obstet Gynecol. 2012, 119, 1113-1118.

20. Rinehart BK, Terrone DA, Hudson C, [et al.]. Lack of utility of standard labor curves in the prediction of progression during labor induction. Am J Obstet Gynecol. 2000, 182, 1520-1526.

21. National Institute for Health and Clinical Excellence (NICE). Intrapartum care for healthy women and babies. 2014. www.nice.org.uk clinical guideline.

22. Vahratian A, Zhang J, Troendle JF, [et al.]. Labour progression and risk of caesarean delivery in electively induced nulliparas. Obstet Gynecol. 2005, 105, 698-704.

23. Vrouenraets FP, Roumen FJ, Dehing CJ, [et al.]. Bishop score and risk of caesarean delivery after induction of labour in nulliparous women. Obstet Gynecol. 2005, 105, 690-697.

24. Cunningham FG, Williams JW. Williams obstetrics. 22nd ed. New York: McGraw-Hill Professional, 2005.

25. American College of Obstetricians and Gynecologists. Dystocia and augmentation of labor. ACOG Practice Bulletin No. 49, December 2003. Obstet Gynecol. 2003, 102, 1445-1454.

26. Menticoglou SM, Hall PF. Routine induction of labor at 41 weeks gestation: noncensus consensus. Br J Obstet Gynaecol. 2002, 109, 485-91. 